\title{
Chronic obstructive pulmonary disease severity influences outcomes after off-pump coronary artery bypass
}

Marcela Viceconte, MSc, ${ }^{\text {a,b }}$ Isadora S. Rocco, MSc, ${ }^{\text {a, }}$ Hayanne O. Pauletti, MSc, ${ }^{\text {a,b }}$ Milena Vidotto, PhD, Ross Arena, $\mathrm{PhD},{ }^{\mathrm{c}}$ Walter J. Gomes, $\mathrm{MD}, \mathrm{PhD},{ }^{\mathrm{a}}$ and Solange Guizilini, $\mathrm{PhD}^{\mathrm{a}, \mathrm{b}}$

\section{ABSTRACT}

Objective: To analyze the impact and severity of chronic obstructive pulmonary disease (COPD) on pulmonary function and postoperative clinical outcome based on the Global Initiative for Obstructive Lung Disease criteria in patients undergoing off-pump coronary artery bypass grafting (CABG).

Methods: Patients were allocated into 3 groups according to presence and severity of COPD: no or mild COPD $(n=144)$; moderate COPD $(n=77)$; and severe COPD $(n=30)$. Spirometry values were obtained preoperatively and on postoperative days (PODs) 2 and 5. The incidences of pneumonia and reintubation, time of mechanical ventilation, and length of postoperative hospital stay were recorded.

Results: Significant impairment in pulmonary function was observed in all groups on PODs 2 and $5(P<.001)$. However, postoperative pulmonary dysfunction was significantly higher in the moderate and severe COPD groups compared with the no or mild COPD group $(P<.05)$. On multivariable analysis, severe COPD was associated with an elevated risk for composite outcomes (odds ratio, 1.37; 95\% confidence interval, $1.20-1.57 ; P<.001$ ). A preoperative forced expiratory volume in 1 second $\left(\mathrm{FEV}_{1}\right)<50 \%$ of the predicted value was associated with poor outcome. A significant negative correlation was found between $\mathrm{FEV}_{1}$ at POD 5 and postoperative length of stay $(r=-0.5 ; P<.001)$.

Conclusions: More severe COPD was associated with greater impairment in pulmonary function and worse clinical outcomes after off-pump CABG surgery. A preoperative $\mathrm{FEV}_{1}<50 \%$ of predicted value appears to be an important predictor of postoperative complications. (J Thorac Cardiovasc Surg 2018;156:1554-61)

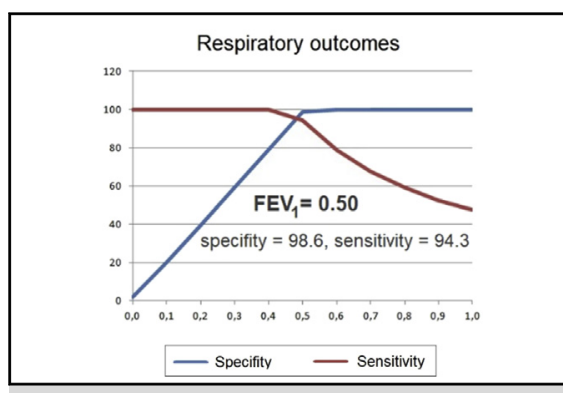

Optimal cutoff point that maximizes the optimal sensitivity and specificity.

\section{Central Message}

Chronic obstructive pulmonary disease severity and preoperative forced expiratory volume in 1 second $<60 \%$ are important predictors of poor outcomes after off-pump coronary artery bypass.

\section{Perspective}

Chronic obstructive pulmonary disease (COPD) severity is poorly graded before cardiac surgery, which leads to underestimated preoperative risks. The GOLD criteria take into account spirometric values to classify COPD, and collectively appear to provide a useful tool for determining preoperative risk in patients with COPD undergoing off-pump coronary artery bypass.

See Editorial Commentary page 1562.

See Editorial page 1552 .
From the ${ }^{\mathrm{a} C a r d i o l o g y}$ and Cardiovascular Surgery Discipline, and ${ }^{\mathrm{b}}$ Department of Human Motion Sciences, Federal University of São Paulo, Santos, Sao Paulo, Brazil; and ${ }^{\mathrm{c}}$ Department of Physical Therapy and Integrative Physiology Laboratory, College of Applied Health Sciences, University of Illinois at Chicago, Chicago, Ill.

Received for publication July 19, 2017; revisions received April 5, 2018; accepted for publication April 19, 2018; available ahead of print May 24, 2018

Address for reprints: Solange Guizilini, PhD, Federal University of Sao Paulo, Rua Napoleão de Barros 715, São Paulo, SP CEP 04023-900, Brazil (E-mail: sguizilini@unifesp.br).

$0022-5223 / \$ 36.00$

Copyright $₫ 2018$ Published by Elsevier Inc. on behalf of The American Association for Thoracic Surgery

https://doi.org/10.1016/j.jtcvs.2018.04.092
Chronic obstructive pulmonary disease (COPD) is closely linked to coronary artery disease, due to a common risk factor. ${ }^{1}$ In the past few years, coronary artery bypass grafting $(\mathrm{CABG})$ has been more routinely performed in high-risk patients, and has proved to be an effective therapeutic option for coronary artery disease. ${ }^{1-3}$ Despite the positive impact of surgery on quality of life and survival, ${ }^{4,5}$ COPD is

- Scanning this $\mathrm{QR}$ code will take you to a supplemental video for the article. 


$\begin{array}{ll}\text { Abbreviations and Acronyms } \\ \text { CABG } & =\text { coronary artery bypass grafting } \\ \text { COPD } & =\text { chronic obstructive pulmonary } \\ & \text { disease } \\ \text { CPB } & =\text { cardiopulmonary bypass } \\ \text { FEV } & =\text { forced expiratory volume in } 1 \text { second } \\ \text { FVC } & =\text { forced vital capacity } \\ \text { GOLD } & =\text { Global Initiative for Obstructive } \\ & \text { Lung Disease } \\ \text { LITA } & =\text { left internal thoracic artery } \\ \text { LOS } & =\text { length of stay } \\ \text { LVEF } & =\text { left ventricular ejection fraction } \\ \text { MARSpline }= & \text { multivariate adaptive regression } \\ & \text { spline } \\ \text { OPCAB } & =\text { off-pump coronary artery bypass } \\ \text { POD } & =\text { postoperative day }\end{array}$

associated with poor prognosis in patients undergoing CABG. ${ }^{6}$ According to EuroSCORE II, COPD is an independent predictor of perioperative mortality. ${ }^{7}$ However, this score does not take disease severity into account, which can lead to a misclassification of preoperative risk. It is possible that the perioperative risk differs among patients across the COPD spectrum (ie, from mild to severe disease).

Regardless of baseline pulmonary function, respiratory mechanics and gas exchange are strongly affected after CABG, increasing the risks of postoperative pulmonary complications. ${ }^{8-10}$ These risks can be further augmented in patients with COPD, in whom the intrinsic and exacerbated inflammatory response may be potentiated by cardiopulmonary bypass (CPB) and other related technical factors. Several previous studies have confirmed the negative influence of severe COPD during the postoperative period in patients undergoing on-pump CABG, as well as its association with higher short- and long-term mortality. ${ }^{1,6,11,12}$ Nevertheless, these results remain controversial due to the heterogeneity of clinical and spirometric variables used to define COPD, which is often diagnosed on an empirical basis without pulmonary function testing. ${ }^{13}$ Moreover, to date no study has clarified the influence of disease severity on pulmonary function and clinical outcomes after CABG, regardless of the use of CPB. Given these gaps in the literature, further investigation is warranted.

The aim of the present investigation was to analyze the impact and severity of COPD on pulmonary function and postoperative clinical outcomes based on the Global Initiative for Obstructive Lung Disease (GOLD) criteria $^{14}$ in patients undergoing off-pump CABG (OPCAB).

\section{METHODS}

This prospective cohort study was performed at Pirajussara and Sao Paulo Hospitals of the Federal University of Sao Paulo after approval by the institutional Ethics Committee. All patients provided written voluntary informed consent.

\section{Study Population}

Patients undergoing OPCAB were evaluated for participation in this study. Inclusion criteria were age 35 to 75 years, coronary artery disease confirmed by coronary angiography, and elective surgery. Patients who had undergone emergency surgery, required on-pump conversion or bilateral pleurotomy, had a diagnosis of restrictive lung disease, or were unable to perform spirometry were excluded from the study. In terms of baseline clinical characteristics, current smokers were defined according to the $\mathrm{Na}-$ tional Health Interview Survey ${ }^{15}$ as adults who smoked at least 100 cigarettes during their lifetime and reported smoking every day or on some days.

A total of 251 patients were allocated into 3 groups according to the presence and severity of COPD: no or mild COPD group $(n=144)$, moderate COPD group $(n=77)$, and severe COPD group $(n=30)$ (Table 1$)$.

\section{Pulmonary Function Assessment}

Forced vital capacity (FVC) and forced expiratory volume in 1 second $\left(\mathrm{FEV}_{1}\right)$ were evaluated at the bedside using a portable spirometer (Spirobank G; Medical International Research, Rome, Italy), according to American Thoracic Society standards. ${ }^{16}$ Pulmonary function testing was carried out preoperatively and on postoperative days (PODs) 2 and 5 by the same evaluator. The severity of COPD was defined according to the GOLD criteria. $^{14}$

\section{Surgical Procedure}

Anesthesia was induced in a routine protocol with etomidate and midazolam and maintained with sufentanil and isoflurane $(0.5 \%-1 \%)$. The OPCAB surgery was carried out through a median sternotomy, using the left internal thoracic artery (LITA) complemented with additional saphenous vein grafts. The LITA was harvested using a skeletonized technique. Meticulous care is routinely taken to preserve the integrity of the pleura during LITA harvesting. In all cases when the pleural cavity was opened incidentally, a soft tubular pleural drain was inserted and positioned in the left costophrenic sinus and exteriorized at the subxyphoid region or at the sixth intercostal space. In all patients, a straight mediastinal drain was placed as well.

In our institution, OPCAB is performed as follows. After provision of systemic heparinization to achieve an activated clotting time of $>250$ seconds, occlusion of the coronary artery was accomplished using a proximal soft silicone snare. Distal anastomoses were accomplished with a 7-0 running polypropylene suture. The vein top ends were attached to the ascending aorta using side-bite clamping. An Octopus 3 suction stabilizer (Medtronic, Minneapolis, Minn) was used in all cases (Video 1).

\section{Postoperative Management}

After surgery, all patients were transferred to the cardiac intensive care unit. Mechanical ventilation settings were adjusted at 12 to 14 breaths per minute, with a fraction of inspired oxygen level necessary to maintain arterial oxygen saturation, a positive end-expiratory pressure of $5 \mathrm{~cm} \mathrm{H}_{2} \mathrm{O}$, and pressure support to maintain a tidal volume of $8 \mathrm{~mL} / \mathrm{kg}$ of predicted body weight. The same analgesic protocol was administered during the first 5 postoperative days (tramadol $100 \mathrm{mg} /$ day), and all patients received the same rehabilitation protocol. Rescue analgesia was supplemented in patients with a pain score of $\geq 4$ on a visual analog scale of 0 to 10 .

\section{Clinical Outcomes}

The duration of mechanical ventilation, postoperative hospital length of stay (LOS), and incidence of pneumonia were recorded. Hospital LOS was defined as the time from operation to hospital discharge. Prolonged mechanical ventilation was defined as the need for respiratory support for 
TABLE 1. COPD classification according to the GOLD standard

\begin{tabular}{ll}
\multicolumn{1}{c}{ Stage } & \multicolumn{1}{c}{ Spirometric values } \\
\hline I: no or mild COPD & $\mathrm{FEV}_{1} / \mathrm{FVC}<70 \%$ and $\mathrm{FEV}_{1} \geq 80 \%$ \\
II: moderate COPD & $\mathrm{FEV}_{1} / \mathrm{FVC}<70 \%$ and $50 \% \leq \mathrm{FEV}_{1}<80 \%$ \\
III: severe COPD & $\mathrm{FEV}_{1} / \mathrm{FVC}<70 \%$ and $30 \% \leq \mathrm{FEV}_{1}<50 \%$ \\
\hline
\end{tabular}

$C O P D$, Chronic obstructive pulmonary disease; $F E V_{l}$, forced expiratory volume in 1 second; $F V C$, forced vital capacity.

$>24$ hours. ${ }^{17}$ Prolonged LOS was defined as a hospital LOS $>14$ days. ${ }^{18}$ Pneumonia was defined by the presence on chest radiographs of new, persistent pulmonary infiltrates not otherwise explained, in combination with at least 2 of the following criteria: body temperature $>38^{\circ} \mathrm{C}$, leukocytosis $\left(>10,000\right.$ cells $\left./ \mathrm{mm}^{3}\right)$, and purulent respiratory secretions. ${ }^{19}$ The main endpoint was respiratory outcomes, composed of reintubation, pneumonia, and prolonged mechanical ventilation.

\section{Statistical Analysis}

The Kolmogorov-Smirnov test was used to verify the normality of data distribution. Categorical data were recorded as absolute (number) and relative (percentage) frequencies and analyzed using the $\chi^{2}$ test or Fisher's exact test. Continuous variables were recorded as mean \pm standard deviation. The groups were compared using analysis of variance with Tukey's post hoc test. Pairwise comparisons were used when multiple comparisons yielded a significant difference $(P<.05)$. The Pearson correlation coefficient was calculated for evaluating the association between POD 5 and $\mathrm{FEV}_{1}$. A logistic regression model was used to assess the impact of different COPD stages on postoperative complications, adjusting for left ventricular ejection fraction (LVEF), body mass index, age, sex, hypertension, diabetes, dyslipidemia, and smoking. Multivariate adaptive regression splines (MARSplines) analysis was performed to evaluate the prognostic performance of $\mathrm{FEV}_{1}$ with regard to respiratory outcomes. The cutoff value was attained as the point corresponding to better sensitivity and specificity. A $P$ value $<.05$ was used to define statistical significance for all tests.

\section{RESULTS}

Over the study period, 327 patients were deemed eligible for the study, of whom 286 were allocated into 3 groups, and 251 completed the analysis. A flowchart indicating the progression of patients throughout the study is shown in Figure 1. Baseline clinical and demographic characteristics of all groups are summarized in Table 2. According to our findings, greater COPD severity was associated with a lower LVEF compared with no or mild COPD $(0.46 \pm 0.05$ vs $0.59 \pm 0.10 ; P<.001)$ and moderate COPD $(0.46 \pm 0.05$ vs $0.58 \pm 0.07 ; P<.01)$ (Table 2$)$.

Significantly impaired FVC and $\mathrm{FEV}_{1}$ was observed in all groups on PODs 2 and 5 compared with preoperative data $(P<.001)$. However, FVC and $\mathrm{FEV}_{1}$ on PODs 2 and 5 were significantly lower in the moderate COPD and severe COPD groups compared with the no or mild COPD group $(P<.05)$. Impairment was significantly greater in the severe COPD group compared with the moderate COPD group (Table 3).

The incidences of reintubation, pneumonia, prolonged mechanical ventilation and increased LOS were higher in

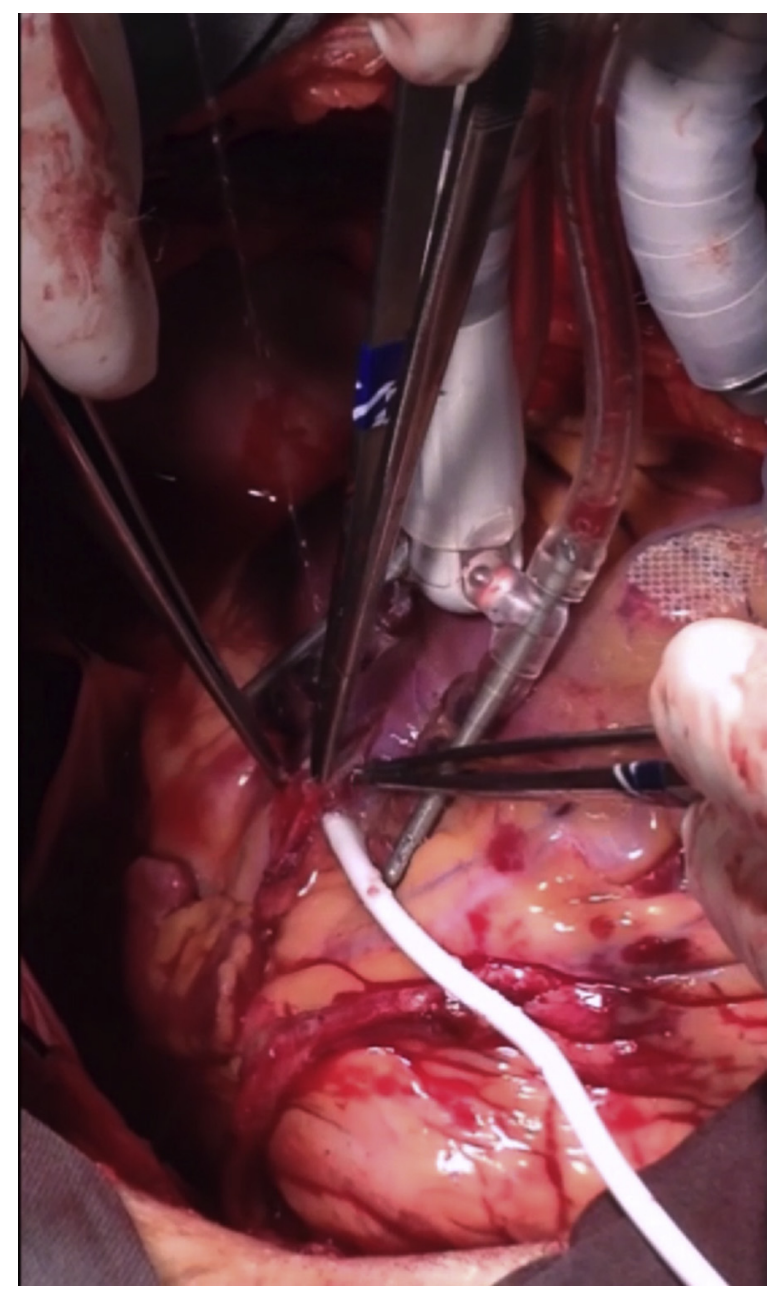

VIDEO 1. Off-pump coronary artery bypass grafting using bilateral internal thoracic arteries (ITAs), with the left ITA anastomosed to the left anterior descending coronary artery and the in situ right ITA routed through the transverse sinus to revascularize the obtuse marginal artery. Video available at: https://www.jtcvs.org/article/S0022-5223(18)31231-5/fulltext.

the severe COPD group compared with the moderate COPD and no or mild COPD groups $(P<.05)$. The moderate COPD group had worse outcomes compared with the no or mild COPD group, with the exception of prolonged mechanical ventilation, for which no significant difference was found (Table 4).

In the multivariable analysis for adjusted odds ratio (OR), moderate and severe COPD were significantly associated with greater risk for respiratory outcomes, especially in severe COPD (OR, 1.13; 95\% CI 1.05-1.23; $P=.002$ and OR, 1.37; 95\% CI, 1.20-1.57; $P<.001$; respectively).

MARSplines analysis demonstrated an optimal cutoff value of $50 \%$ of predicted $\mathrm{FEV}_{1}$ for respiratory outcomes (Table 5 and Figure 2). A significant negative correlation was found between $\mathrm{FEV}_{1}$ at POD 5 and postoperative hospital LOS $(r=-0.50 ; P<.001)$. 


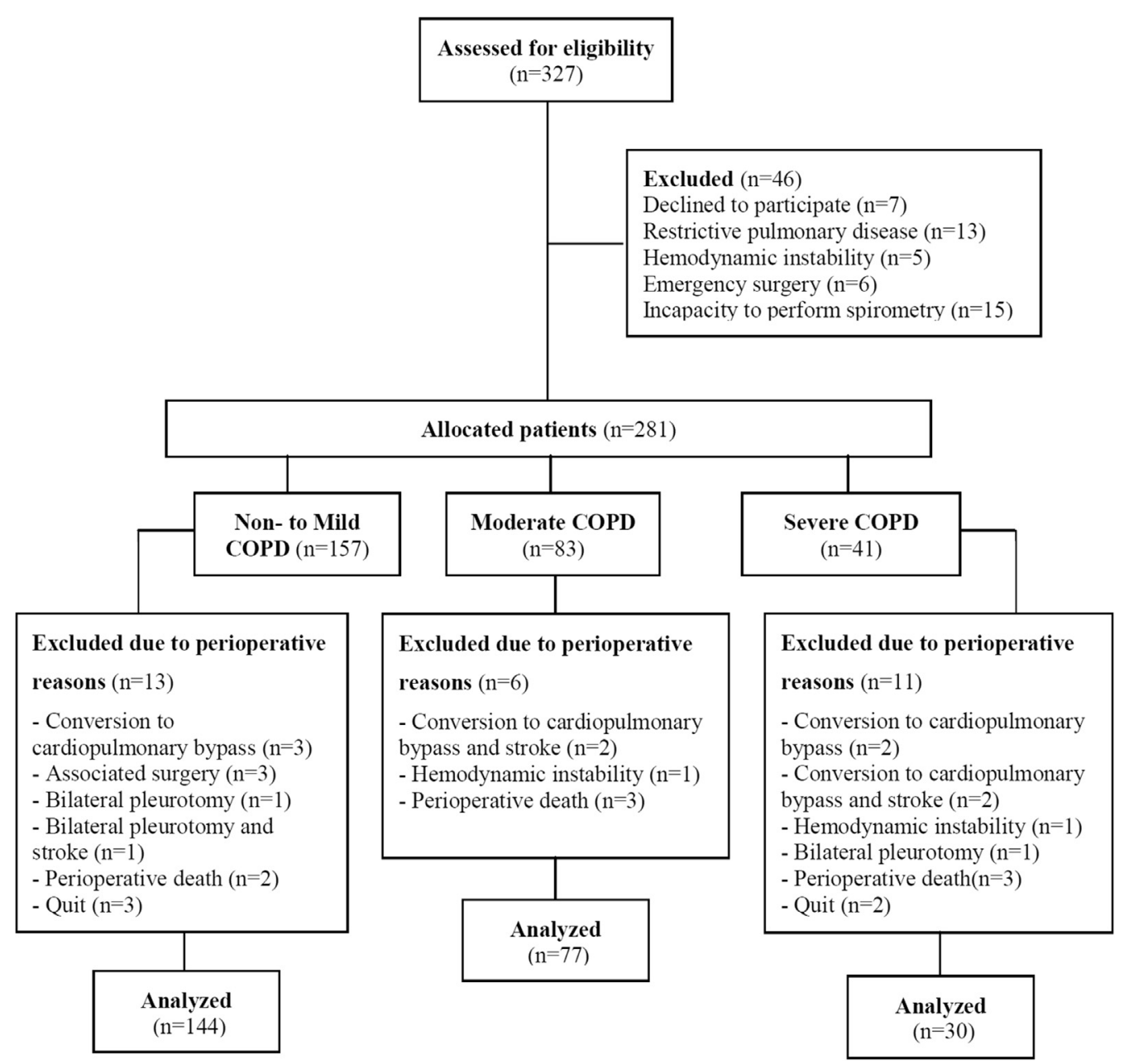

FIGURE 1. Flowchart of progression of patients. $C O P D$, Chronic obstructive pulmonary disease.

\section{DISCUSSION}

The current study revealed that the presence and severity of COPD, based on GOLD criteria, was associated with greater impairment in pulmonary function and worse clinical outcomes in patients undergoing OPCAB. In addition, preoperative $\mathrm{FEV}_{1}<50 \%$ seems to be an important predictor for poor outcomes.

Few studies have evaluated the lung function in COPD patients and their influence during the perioperative period of CABG. To our knowledge, this is the first prospective study evaluating preoperative pulmonary function, based on GOLD definitions and the influence of COPD severity on pulmonary function and clinical outcomes after OPCAB.

Pulmonary function is strongly affected after heart surgery, owing to inherent factors associated with surgical procedures. The use of general anesthesia and median sternotomy results in decreased lung compliance and increased respiratory system resistance, inducing postoperative lung dysfunction. ${ }^{8,9,20,21}$ Pulmonary dysfunction is more pronounced when LITA is used, especially if associated with pleura opening with a consequent need for intercostal pleural drainage, further damaging lung function compared with maintenance of an intact pleura. ${ }^{10}$ Furthermore, on-pump CABG also elicits a greater degree of lung dysfunction in the early postoperative period compared with $\mathrm{OPCAB}$, owing to the consequent inflammatory response ${ }^{22,23}$ Despite the outcomes of the CORONARY trial, in which no differences between on-pump and off-pump surgery were seen in the rate of the composite outcome, the impact of pulmonary function and COPD has not been assessed and reported ${ }^{24}$ Evidence suggests that high-risk patients may benefit from avoiding the deleterious effects of $\mathrm{CPB} .^{25,26}$ In a retrospective analysis, Lizak and colleagues ${ }^{27}$ found better outcomes in patients with COPD undergoing OPCAB compared with those undergoing conventional CABG.

In addition to surgical factors, pre-existing conditions, such as COPD, may potentiate the effects of surgery on pulmonary function and postoperative outcomes. Recent studies have demonstrated that CABG has a positive impact on quality of life in patients with concomitant 
TABLE 2. Preoperative and intraoperative clinical and demographic characteristics

\begin{tabular}{|c|c|c|c|}
\hline Characteristic & $\begin{array}{l}\text { No or mild COPD } \\
\quad(n=144)\end{array}$ & $\begin{array}{c}\text { Moderate COPD } \\
(\mathbf{n}=77)\end{array}$ & $\begin{array}{c}\text { Severe COPD } \\
\quad(\mathbf{n}=\mathbf{3 0})\end{array}$ \\
\hline Age, $y$, mean \pm SD & $59.7 \pm 10$ & $61 \pm 10$ & $63 \pm 11$ \\
\hline \multicolumn{4}{|l|}{ Sex, n $(\%)$} \\
\hline Male & $122(84.7)$ & $67(87.0)$ & $25(83.0)$ \\
\hline Female & $22(15.3)$ & $10(13.0)$ & $05(17.0)$ \\
\hline $\mathrm{LVEF}$, mean $\pm \mathrm{SD}$ & $0.59 \pm 0.10$ & $0.58 \pm 0.07^{*}$ & $0.46 \pm 0.05^{*}, \dagger$ \\
\hline \multicolumn{4}{|l|}{ Comorbidities, n (\%) } \\
\hline LVEF $<0.45$ & $15(10.4)$ & $9(11.6)^{*}$ & $14(46.6)^{*}, \dagger$ \\
\hline Current smoker & $36(25.0)$ & $34(44.0)$ & $12(42.0)$ \\
\hline Hypertension & $93(64.5)$ & $52(67.5)$ & $18(60.0)$ \\
\hline Diabetes & $43(29.8)$ & $25(32.4)$ & $8(26.7)$ \\
\hline Hypercholesterolemia & $87(60.4)$ & $48(62.3)$ & $20(66.6)$ \\
\hline \multicolumn{4}{|l|}{ Pulmonary function, mean \pm SD } \\
\hline FVC, $\mathrm{L}$ & $3.5 \pm 0.7$ & $3.0 \pm 0.4$ & $3.5 \pm 0.5$ \\
\hline$\%$ pred & $88 \pm 13$ & $80 \pm 13$ & $90 \pm 11$ \\
\hline $\mathrm{FEV}_{1}, \mathrm{~L}$ & $2.8 \pm 0.6$ & $1.8 \pm 0.3^{*}$ & $1.3 \pm 0.3^{*}, \dagger$ \\
\hline$\%$ pred & $89.2 \pm 14.4$ & $59.7 \pm 7.4$ & $42.7 \pm 7.0$ \\
\hline $\mathrm{FEV}_{1} / \mathrm{FVC}$ & $81 \pm 8$ & $60 \pm 7 *$ & $39 \pm 9^{*}, \dagger$ \\
\hline EuroSCORE, mean $\pm \mathrm{SD}$ & $3.2 \pm 1.8$ & $3.7 \pm 2.0$ & $4.1 \pm 3.1$ \\
\hline \multicolumn{4}{|l|}{ Pleural drain site, n (\%) } \\
\hline Intercostal & $55(38)$ & $28(36)$ & $12(40)$ \\
\hline Subxyphoid & $89(62)$ & $49(64)$ & $18(60)$ \\
\hline Duration of surgery, min, mean $\pm \mathrm{SD}$ & $296 \pm 22$ & $309 \pm 19$ & $307 \pm 21$ \\
\hline Grafts per patient, $n$, mean \pm SD & $2.1 \pm 0.7$ & $2.3 \pm 0.8$ & $2.2 \pm 0.4$ \\
\hline
\end{tabular}

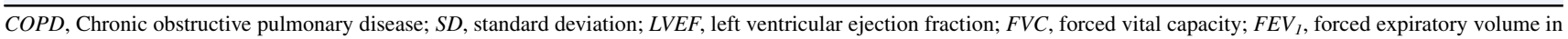
1 second; \% pred, percentage of predicted; $S D$, standard deviation. ${ }^{*} P<.001$ versus no or mild COPD. $\dagger P<.01$ versus moderate COPD.

COPD. ${ }^{5}$ According to EuroSCORE II $^{7}$ and Syntax II score, ${ }^{28} \mathrm{COPD}$ is an independent risk factor for morbidity and mortality postsurgery and is associated with poor prognosis. ${ }^{1,6,11,12}$ However, these scores do not take into account disease severity, and it is possible that perioperative risk differs according to the severity of COPD (ie, from mild to moderate or severe). Few studies used spirometric tests before cardiac surgery in COPD patients, and thus particularly novel aspects of our study are the use of systematic perioperative spirometry evaluation, use of the GOLD criteria, and evaluation of the influence of COPD severity on spirometric values and clinical outcomes.

In the present study, regardless of preoperative pulmonary function or COPD severity, all groups presented with significantly impaired $\mathrm{FVC}$ and $\mathrm{FEV}_{1}$ at PODs 2 and 5 compared with preoperative values. These results are similar to those reported in previous studies. ${ }^{8-10,19}$ However, postoperative spirometric values were significantly lower in the moderate and severe COPD groups compared with the no or mild COPD group, and the severe COPD group exhibited significantly greater postoperative pulmonary dysfunction compared with the moderate COPD group.

The evidence indicates that a greater degree of pulmonary dysfunction increases the risk of postoperative complications. Our results are consistent with previous studies $^{19,21,27}$ showing that patients with advanced-stage COPD exhibited greater pulmonary dysfunction and poorer outcomes following OPCAB. These results are supported

TABLE 3. Pulmonary function values on PODs 2 and 5

\begin{tabular}{lccccccc}
\hline & \multicolumn{3}{c}{ POD 2 } & & \multicolumn{3}{c}{ POD 5 } \\
\cline { 2 - 4 } \multicolumn{1}{c}{ Parameter } & $\begin{array}{c}\text { No or mild COPD } \\
(\mathbf{n}=\mathbf{1 4 4})\end{array}$ & $\begin{array}{c}\text { Moderate COPD } \\
(\mathbf{n}=\mathbf{7 7})\end{array}$ & $\begin{array}{c}\text { Severe COPD } \\
(\mathbf{n}=\mathbf{3 0})\end{array}$ & $\begin{array}{c}\text { No or mild COPD } \\
(\mathbf{n}=\mathbf{1 4 4})\end{array}$ & $\begin{array}{c}\text { Moderate COPD } \\
(\mathbf{n}=\mathbf{7 7})\end{array}$ & $\begin{array}{c}\text { Severe COPD } \\
(\mathbf{n}=\mathbf{3 0})\end{array}$ \\
\hline $\mathrm{FVC}, \%$, mean $\pm \mathrm{SD}$ & $45.5 \pm 12.8$ & $37.2 \pm 6.3^{*}$ & $27.4 \pm 7.9^{*}, \dagger$ & & $74.8 \pm 16.5$ & $55.2 \pm 9.1^{*}$ & $45.7 \pm 7.9^{*}, \dagger$ \\
$\mathrm{FEV}_{1}, \%$, mean $\pm \mathrm{SD}$ & $43.6 \pm 13.4$ & $38.4 \pm 8.6^{*}$ & $32.7 \pm 8.6^{*}, \dagger$ & & $68.7 \pm 16.7$ & $60.8 \pm 16.9^{*}$ & $52.4 \pm 13.5^{*}, \dagger$ \\
\hline
\end{tabular}

$\mathrm{FVC}$ and $\mathrm{FEV}_{1}$ are expressed as percentage of preoperative baseline value. $P O D$, Postoperative day; $C O P D$, chronic obstructive pulmonary disease; $F V C$, forced vital capacity; $F E V_{l}$, forced expiratory volume in 1 second; $S D$, standard deviation. $* P<.001$ versus no or mild COPD. $\nmid P<.05$ versus moderate COPD. 
TABLE 4. Postoperative outcomes

\begin{tabular}{|c|c|c|c|}
\hline Outcome & $\begin{array}{c}\text { No or mild COPD } \\
\quad(n=144)\end{array}$ & $\begin{array}{l}\text { Moderate COPD } \\
\quad(\mathbf{n}=77)\end{array}$ & $\begin{array}{c}\text { Severe COPD } \\
\quad(\mathbf{n}=\mathbf{3 0})\end{array}$ \\
\hline Respiratory outcomes, n (\%) & $13(9.0)$ & $28(36.4)$ & $25(83.3)^{*}, \dagger$ \\
\hline Prolonged mechanical ventilation, $\mathrm{n}(\%)$ & $5(3.5)$ & $6(7.7)$ & $10(33.3)^{*}, \dagger$ \\
\hline Reintubation, $\mathrm{n}(\%)$ & $1(0.7)$ & $11(14.2)^{*}$ & $5(16.6)^{*}, \dagger$ \\
\hline Pneumonia, n (\%) & $7(4.8)$ & $11(14.2)^{*}$ & $10(33.3)^{*}, \dagger$ \\
\hline Hospital LOS, d, mean \pm SD & $6.2 \pm 1.6$ & $8.9 \pm 2.4^{*}$ & $12.6 \pm 5.1^{*}, \dagger$ \\
\hline Prolonged LOS, n (\%) & $0(0)$ & 9 (11.6)* & $13(43.4)^{*}, \dagger$ \\
\hline
\end{tabular}

$C O P D$, Chronic obstructive pulmonary disease; $L O S$, length of stay; $S D$, standard deviation. $* P<.01$ versus no or mild COPD. $\dagger P<.05$ versus moderate COPD.

by the significant negative correlation between $\mathrm{FEV}_{1}$ at POD 5 and postoperative LOS.

Previous studies demonstrated an association between COPD and postoperative morbidity and mortality. ${ }^{11,12,29}$ However, the heterogeneity of clinical spirometric variables used to define COPD led to controversial results. Ivanov and colleagues ${ }^{30}$ evaluated 1412 patients undergoing cardiac surgery and concluded that the Society of Thoracic Surgeon score and pulmonary function tests offer modest discriminatory ability to predict respiratory failure, prolonged postoperative LOS, and 30-day all-cause mortality. However, pulmonary function tests were not performed routinely, and the physicians were not blinded to spirometric results and might have modified treatment strategies.

Manganas and colleagues ${ }^{31}$ retrospectively evaluated patients with COPD after CABG and found that severe COPD was associated with a higher incidence of pneumonia with no difference in mortality and hospital LOS. However, patients with mild and moderate COPD were included in the same group, potentially confounding the results. In our study, both moderate and severe COPD were associated with a higher incidence of pneumonia. Another study ${ }^{32}$ demonstrated a significantly higher mortality risk with moderate and severe COPD, but spirometry was not routinely performed before cardiac surgery in either study.

Our results indicate that the greater the COPD severity, the greater the impairment in postoperative pulmonary function and, consequently, the worse the outcomes after $\mathrm{OPCAB}$. These findings could be explained by the pathophysiology of the disease. COPD progresses with intrinsic changes in respiratory mechanics and gas exchange, as well as chronic inflammation. ${ }^{14}$ This baseline pulmonary dysfunction was likely potentiated by the operation.
The preoperative $\mathrm{FEV}_{1}$ value must be established as a major prognostic factor for postoperative complications after CABG, ${ }^{12}$ given its association with increased LOS and morbidity and mortality. ${ }^{27}$ Our study corroborates these findings; the adjusted OR for patients with severe COPD $\left(\mathrm{FEV}_{1}<50 \%\right)$ indicates an elevated risk for developing respiratory outcomes (ie, pneumonia, reintubation, and prolonged mechanical ventilation), increasing LOS. Our MARSplines analysis identified a preoperative $\mathrm{FEV}_{1}$ cutoff value of approximately $50 \%$ of the predicted value as a significant marker for complications following CABG.

In this context, the lack of COPD severity stratification can lead to a misanalysis of preoperative risk, highlighting the clinical importance of preoperative GOLD stratification with $\mathrm{FEV}_{1}$ evaluation. Recently published guidelines emphasize the importance of spirometry as the gold standard for the diagnosis and staging of severity in patients with COPD; thus, we strongly recommend routine spirometry assessment before cardiac surgery for risk stratification and for specific treatment planning by health professionals.

This study has several limitations. First, the clinicians were not blinded to the spirometry data, which might have influenced postoperative management. Second, almost all of our study patients were male, and the results may differ for female patients. Third, we found that a greater severity of COPD was associated with a lower LVEF, confirming the findings of previous studies. ${ }^{6}$ The fact that LVEF differed across groups might have influenced our results. Nonetheless, severe COPD is associated with lower LVEF and advanced coronary artery disease, likely related to common risk factors linked to their emergence, such as heavy smoking.

TABLE 5. MARSplines analysis to evaluate the prognostic performance of $\mathrm{FEV}_{1}$ with regard to respiratory outcomes

\begin{tabular}{lcccc}
\hline Variable & OR & $\mathbf{9 5} \%$ CI & $\boldsymbol{\beta}$ value & \multicolumn{1}{c}{ v value } \\
\hline FEV $_{1}$ & 0.992 & $0.987-1.004$ & -0.008 & .001 \\
Age & 0.948 & $0.847-1.061$ & -0.054 & .350 \\
BMI & 0.925 & $0.826-1.035$ & -0.078 & .172 \\
LVEF & 0.784 & $0.697-0.883$ & -0.244 & .003 \\
\hline
\end{tabular}

$O R$, Odds ratio; $C I$, confidence interval; $F E V_{l}$, forced expiratory volume in 1 second; $B M I$, body mass index; $L V E F$, left ventricular ejection fraction. 


\section{Respiratory outcomes}

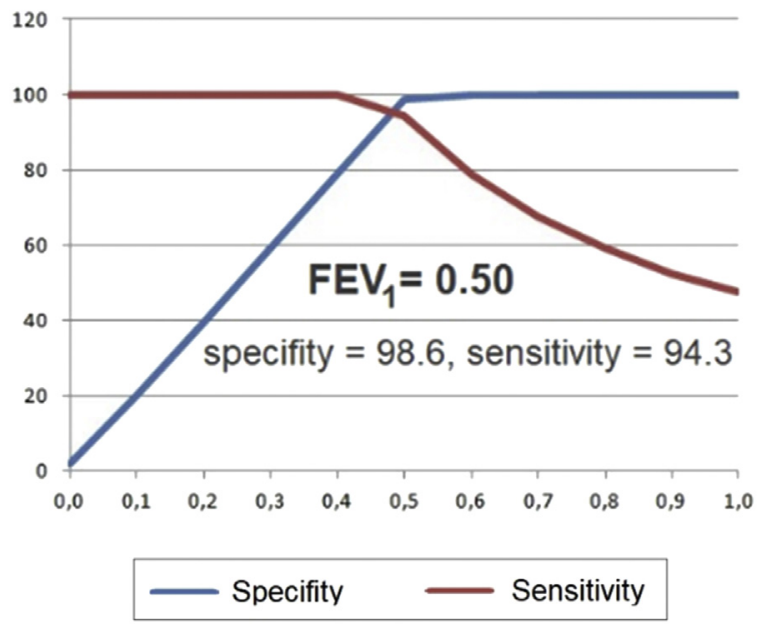

FIGURE 2. Best found cutoff point that maximizes the optimal sensitivity and specificity for respiratory outcomes. The confounders included in the model were age, body mass index, and left ventricular ejection fraction. $F E V_{l}$, Forced expiratory volume in 1 second.

In conclusion, increased COPD severity was associated with a greater impairment in pulmonary function and worse clinical outcomes in the early postoperative period after OPCAB. A preoperative $\mathrm{FEV}_{1}<50 \%$ of the predicted value appears to be an important prognostic marker of postoperative complications after surgical myocardial revascularization. Therefore, the preoperative use of spirometry for COPD severity stratification may help refine currently used operative risk scores.

\section{Conflict of Interest Statement}

Authors have nothing to disclose with regard to commercial support.

We thank Rosa M. N. Marcusso for her invaluable assistance with the statistical analysis.

\section{References}

1. Leavitt BJ, Ross CS, Spence B, Surgenor SD, Olmstead EM, Clough RA, et al. Long-term survival of patients with chronic obstructive pulmonary disease undergoing coronary artery bypass surgery. Circulation. 2006;114(1 Suppl):I430-4.

2. Velazquez EJ, Lee KL, Jones RH, Al-Khalidi HR, Hill JA, Panza JA, et al. Coronary-artery bypass surgery in patients with ischemic cardiomyopathy. $N$ Engl $J$ Med. 2016;374:1511-20.

3. Güler M, Kirali K, Toker ME, Bozbuğa N, Ömeroğlu SN, Akinci E, et al. Different $\mathrm{CABG}$ methods in patients with chronic obstructive pulmonary disease. Ann Thorac Surg. 2001;71:152-7.

4. Medalion B, Katz MG, Cohen AJ, Hauptman E, Sasson L, Schachner A. Longterm beneficial effect of coronary artery bypass grafting in patients with COPD. Chest. 2004;125:56-62.

5. O'Boyle F, Mediratta N, Chalmers J, Al-Rawi O, Mohan K, Shaw M, et al. Longterm survival of patients with pulmonary disease undergoing coronary artery bypass surgery. Eur J Cardiothorac Surg. 2013;43:697-703.

6. Saleh HZ, Mohan K, Shaw M, Al-Rawi O, Elsayed H, Walshaw M, et al. Impact of chronic obstructive pulmonary disease severity on surgical outcomes in patients undergoing non-emergent coronary artery bypass grafting. Eur J Cardiothorac Surg. 2012;42:108-13; discussion 113.

7. Biancari F, Vasques F, Mikkola R, Martin M, Lahtinen J, Heikkinen J. Validation of EuroSCORE II in patients undergoing coronary artery bypass. Ann Thorac Surg. 2012;93:1930-5.

8. Guizilini S, Bolzan DW, Faresin SM, Ferraz SF, Tavolaro K, Cancio AA, et al. Pleurotomy with subxyphoid pleural drain affords similar effects to pleural integrity in pulmonary function after off-pump coronary artery bypass graft. $J$ Cardiothorac Surg. 2012;7:11.

9. Wynne R, Botti M. Postoperative pulmonary dysfunction in adults after cardiac surgery with cardiopulmonary bypass: clinical significance and implications for practice. Am J Crit Care. 2004;13:384-93.

10. Guizilini S, Gomes WJ, Faresin SM, Bolzan DW, Buffolo E, Carvalho AC, et al. Influence of pleurotomy on pulmonary function after off-pump coronary artery bypass grafting. Ann Thorac Surg. 2007;84:817-22.

11. Nishiyama K, Morimoto T, Furukawa Y, Nakagawa Y, Ehara N, Taniguchi R, et al. Chronic obstructive pulmonary disease-an independent risk factor for long-term cardiac and cardiovascular mortality in patients with ischemic heart disease. Int J Cardiol. 2010;143:178-83.

12. Fuster RG, Argudo JA, Albarova OG, Sos FH, López SC, Codoñer MB, et al. Prognostic value of chronic obstructive pulmonary disease in coronary artery bypass grafting. Eur J Cardiothorac Surg. 2006;29:202-9.

13. Bednarek M, Maciejewski J, Wozniak M, Kuca P, Zielinski J. Prevalence, severity and underdiagnosis of COPD in the primary care setting. Thorax. 2008;63:402-7.

14. Vestbo J, Hurd SS, Agustí AG, Jones PW, Vogelmeier C, Anzueto A, et al. Global strategy for the diagnosis, management, and prevention of chronic obstructive pulmonary disease: GOLD executive summary. Am J Respir Crit Care Med. 2013; 187:347-65.

15. Jamal A, King BA, Neff LJ, Whitmill J, Babb SD, Graffunder CM. Current cigarette smoking among adults-United States, 2005-2015. MMWR Morb Mortal Wkly Rep. 2016;65:1205-11.

16. Miller MR, Hankinson J, Brusasco V, Burgos F, Casaburi R, Coates A, et al. Standardization of spirometry. Eur Respir J. 2005;26:319-38.

17. Gumus F, Polat A, Yektas A, Totoz T, Bagci M, Erentug V, et al. Prolonged mechanical ventilation after CABG: risk factor analysis. J Cardiothorac Vasc Anesth. 2015;29:52-8.

18. Peterson ED, Coombs LP, Ferguson TB, Shroyer AL, DeLong ER, Grover FL, et al. Hospital variability in length of stay after coronary artery bypass surgery: results from the Society of Thoracic Surgeons' national cardiac database. Ann Thorac Surg. 2002; 74:464-73.

19. Bolzan DW, Trimer R, Begot I, Nasrala ML, Forestieri P, Mendez VM, et al. Open-lung ventilation improves clinical outcomes in off-pump coronary artery bypass surgery: a randomized controlled trial. J Cardiothorac Vasc Anesth. 2016;30:702-8.

20. Badenes R, Lozano A, Belda FJ. Postoperative pulmonary dysfunction and mechanical ventilation in cardiac surgery. Crit Care Res Pract. 2015;2015: 420513.

21. Guizilini S, Alves DF, Bolzan DW, Cancio AS, Regenga MM, Moreira RS, et al. Sub-xyphoid pleural drain as a determinant of functional capacity and clinical results after off-pump coronary artery bypass surgery: a randomized clinical trial. Interact Cardiovasc Thorac Surg. 2014;19:382-7.

22. Carmona P, Paredes F, Mateo E, Mena-Durán AV, Hornero F, Martínez-León J. Is off-pump technique a safer procedure for coronary revascularization? A propensity score analysis of 20 years of experience. Interact Cardiovasc Thorac Surg. 2016;22:612-9.

23. Ascione R, Lloyd CT, Underwood MJ, Lotto AA, Pitsis AA, Angelini GD. Inflammatory response after coronary revascularization with or without cardiopulmonary bypass. Ann Thorac Surg. 2000;69:1198-204.

24. Lamy A, Devereaux PJ, Prabhakaran D, Taggart DP, Hu S, Straka Z, et al. Fiveyear outcomes after off-pump or on-pump coronary-artery bypass grafting. $N$ Engl J Med. 2016;375:2359-68.

25. Al-Ruzzeh S, Ambler G, Asimakopoulos G, Omar RZ, Hasan R, Fabri B, et al. Off-pump coronary artery bypass (OPCAB) surgery reduces riskstratified morbidity and mortality: a United Kingdom multi-center comparative analysis of early clinical outcome. Circulation. 2003; 108(Suppl I):II1-8.

26. Kerendi F, Halkos ME, Puskas JD, Lattouf OM, Kilgo P, Guyton RA, et al. Impact of off-pump coronary artery bypass graft surgery on postoperative pulmonary complications in patients with chronic lung disease. Ann Thorac Surg. 2011; 91:8-15. 
27. Lizak MK, Nash E, Zakliczyński M, Śliwka J, Knapik P, Zembala M. Additional spirometry criteria predict postoperative complications after coronary artery bypass grafting (CABG) independently of concomitant chronic obstructive pulmonary disease: when is off-pump CABG more beneficial? Pol Arch Med Wewn. 2009; 119:550-7.

28. Farooq V, van Klaveren D, Steyerberg EW, Meliga E, Vergouwe Y, Chieffo A, et al. Anatomical and clinical characteristics to guide decision making between coronary artery bypass surgery and percutaneous coronary intervention for individual patients: development and validation of SYNTAX score II. Lancet. 2013; 381:639-50.
29. Efird JT, Griffin W, O’Neal WT, Davies SW, Shiue KY, Grzybowski M, et al Long-term survival after cardiac surgery in patients with chronic obstructive pulmonary disease. Am J Crit Care. 2016;25:266-76.

30. Ivanov A, Yossef J, Tailon J, Worku BM, Gulkarov I, Tortolani AJ, et al. Do pulmonary function tests improve risk stratification before cardiothoracic surgery? J Thorac Cardiovasc Surg. 2016;151:1183-9.e3.

31. Manganas H, Lacasse Y, Bourgeois S, Perron J, Dagenais F, Maltais F. Postoperative outcome after coronary artery bypass grafting in chronic obstructive pulmonary disease. Can Respir J. 2007;14:19-24.

32. Adabag AS, Wassif HS, Rice K, Mithani S, Johnson D, Bonawitz-Conlin J, et al Preoperative pulmonary function and mortality after cardiac surgery. Am Heart J. 2010;159:691-7.

Readers who found these articles interesting may also like to read the following papers found in recent and future issues of our sister publications, Seminars in Thoracic and Cardiovascular Surgery and Operative Techniques in Thoracic and Cardiovascular Surgery!

\section{Adult: Perioperative Management}

ORIGINAL SUBMISSION: Early Outcomes with Rapid- Deployment Versus Stented Biological Valves: A Propensity-Match Analysis. Anthony Nguyen. Semin Thoracic Surg 2018:16-23.

Editorial Commentary: Rapid-Deployment Aortic Valve Replacement: Clear BenefitsWithout a Clear Target Patient Population. Craig M. Jarrett. Semin Thoracic Surg 2018:24-25.

ORIGINAL SUBMISSION: Randomized Trial of Carnitine for the Prevention of Perioperative Atrial Fibrillation. Farzaneh Dastan. Semin Thoracic Surg 2018:7-13.

Editorial Commentary: Preventing Postoperative Atrial Fibrillation: Is There One Best Option? Vincent R. Conti. Semin Thoracic Surg 2018:14-15. 